\section{Antecedentes de la teoría del crimen y el castigo en los Fundamentos de la Filosofía del derecho}

\author{
Antecedents of the Theory of Crime and Punishment in the Elements of the \\ Philosophy of Right
}

Ana María Miranda Mora

\section{RESUMEN}

En este artículo se reconstruyen algunos antecedentes de la teoría del crimen y el castigo de la filosofía del derecho de Hegel la luz de la pregunta por el rol de la coerción en su justificación del castigo penal y su noción de derecho. Se muestra cómo la discusión normativa sobre el castigo y el crimen implica en su filosofía, la pregunta por la legitimidad del derecho penal para enforzar (to enforce) la ley por medio del castigo. Asimismo, se ubica el análisis de Hegel como parte de la reforma llustrada de la pena y se propone entender su teoría como una teoría mixta, en contraste con las teorías que afirman una lectura prioritariamente retributivista. El objetivo de este artículo es analizar el contexto teórico y los antecedentes históricos de su teoría del crimen y el castigo que cristalizan en los Fundamentos de la filosofía del Derecho de Berlín. Para concluir, se argumenta que la teoría de Hegel es una teoría mixta, es decir, que combina su carácter retributivo con funciones sociales adicionales, como la disuasión y la rehabilitación, y se rechaza la tesis que sostiene que la teoría más sustantiva del castigo de Hegel está contenida en el Derecho Abstracto. Asimismo, se muestra que la justificación completa de la legitimación de la pena (Strafe) sólo se alcanza en la dimensión de la Administración de la justicia en el apartado de la Sociedad Civil.

Palabras clave: teoría del crimen; Hegel; castigo penal

\section{ABSTRACT}

This article reconstructs some of the antecedents of Hegel's theory of crime and punishment in the philosophy of law in the light of the question of the role of coercion in his justification of criminal punishment and his notion of law. It is shown how the normative discussion of punishment and crime implies in his philosophy the question of the legitimacy of criminal law to enforce the law by means of punishment. Likewise, Hegel's analysis is placed as part of the Enlightenment reform of punishment, and it is proposed to understand his theory as a mixed theory, in contrast with theories that affirm a primarily retributivist reading. The aim of this article is to analyze the theoretical context and historical background of his theory of crime and punishment crystallized in the Berlin Foundations of the Philosophy of Right. To conclude, it is argued that Hegel's theory is a mixed theory, i.e., that it combines its retributive character with additional social functions, such as deterrence and rehabilitation, and the thesis that Hegel's most substantive theory of punishment is contained in Abstract Law is rejected. It is also shown that the full justification of the legitimation of punishment (Strafe) is only achieved in the dimension of the Administration of Justice in the Civil Society section.

Keywords: theory of crime; Hegel; punishment
INFORMACIÓN

https://doi.org/10.46652/resistances.v2i4.68 ISSN $2737-6222$ |

Vol. 2 No. 4, 2021, e21068

Quito, Ecuador

Enviado: octubre 30, 2021 Aceptado: diciembre 16, 2021 Publicado: diciembre 28, 2021 Publicación continua

Sección dossier | Peer Reviewed

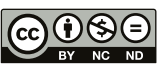

open 2 access

AUTOR

Ana María Miranda Mora Alice Salomon Hochschule Berlin - Alemania miranda@ash-berlin.eu

Conflicto de intereses

La autora declara que no existe conflicto de interés posible.

Financiamiento

No existió asistencia financiera de partes externas al presente artículo.

Agradecimiento

N/A

Nota

El artículo es producto de una publicación de tesis de doctorado.

PUBLISHER 


\section{La reforma Ilustrada del castigo}

En la esfera del derecho penal, el castigo es impuesto por la institución del derecho ante una violación de la ley. El derecho penal es el orden normativo que establece las acciones u omisiones que serán consideradas como delitos. La discusión sobre la justificación del castigo se remonta al siglo XVIII (Foucault, 2018; Dübgen, 2016) en el marco de la llustración y se organiza alrededor de diferentes teorías y enfoques, cada uno de los cuales explica la transformación del castigo, pero también su permanencia y eficacia. Mientras que las teorías normativas (jurídico-filosóficas) justifican el castigo en términos de objetivos absolutos, es decir, evaluando los castigos de acuerdo con criterios como la justicia o sus propósitos (fines); las teorías sociales analizan la persistencia y la transformación del castigo en términos de las funciones que tiene para la sociedad. Este tipo de análisis se distingue de las investigaciones empíricas o psicológicas que cuestionan, por ejemplo, la capacidad de un individuo de ser culpable o delincuente (Dübgen, 2016). El debate normativo sobre el castigo y el crimen que aquí se discute, implica la pregunta por la legitimidad normativa y la autoridad del derecho penal para hacer cumplir la ley por medio del castigo. La discusión se estructura en torno a las teorías relativas y absolutas del castigo, mejor conocidas como teorías utilitaristas y retributivista, respectivamente (Hinchman, 1982).

Las teorías relativas o utilitaristas justifican el castigo por los beneficios que aportan a la comunidad. Se dirigen al futuro y tienen como objetivo prevenir nuevas violaciones de la ley. Estas teorías argumentan que el castigo, ya sea como institución o considerando un caso en específico, sólo puede justificarse si se puede demostrar que produce una ventaja para la felicidad general, bienestar o seguridad social. Al concentrarse casi exclusivamente en las consecuencias del castigo (por ejemplo, en su efecto disuasivo o preventivo), estas teorías permanecen sensibles a las críticas que cuestionan la pertinencia del castigo para los efectos que se reclaman. Así, un defensor del enfoque utilitarista puede convertirse en un defensor del tratamiento o corrección de los delincuentes si la consecuencia que se busca - la seguridad pública- puede lograrse de manera más fiable mediante el tratamiento (médico, por ejemplo) que por medio del castigo. Si aceptamos que la imposición del sufrimiento o la privación de la libertad es un mal, el utilitarista debe de poder demostrar que algún bien, como la disuasión y el control, superaría el supuesto mal (introducido por el crimen), lo cual demostraría la racionalidad del castigo.

En contraste, la postura retributivista o absoluta justifica el castigo siguiendo consideraciones que apelan a un valor absoluto, como la justicia o al propósito inmanente del castigo como modo de retribución, y no por sus consecuencias. Las teorías criminales retributivista ubican el significado y el propósito del castigo en la reacción retroactiva a un acto del pasado. La ley, se argumenta, difiere de una mera sugerencia o recomendación precisamente porque las sanciones van unidas a ella. Es decir, sostener que el castigo debe ser aplicado a los infractores de la ley implica un juicio analítico sobre el concepto mismo de la ley (Hinchman, 1982). Además, sostienen que sólo su teoría demuestra la absoluta injusticia de castigar a un inocente. La postura utilitarista, bajo la consigna de promover la mayor felicidad para el mayor número, aceptaría castigar a un hombre inocente, si bajo ciertas circunstancias, contribuye a ese fin. El 
retributivista no cae en el mismo problema, ya que éste trata de justificar la necesaria relación entre crimen y castigo. Es decir, solo el que infringe una ley, merece ser castigado; del mismo modo, se evitará castigar a quien no haya cometido un crimen.

Jeremy Bentham (1748-1832) y, el jurista y filósofo italiano, Cesare Beccaria (1738-1794) son dos de los principales representantes que cuestionaron el sistema de castigo medieval. Beccaria es uno de los primeros en preguntarse en De los delitos y las penas (1764) por la legitimidad del derecho para castigar y en discutir la eficacia y la coherencia del castigo para disuadir a los potenciales perpetradores. Beccaria no tenía la intención de cuestionar la legitimidad del castigo, sino de justificar sistemáticamente el castigo en general, dicho de otra forma, justificarlo filosóficamente y contrarrestar y controlar la contingencia del castigo implicada en la noción de poder absoluto o soberano. Los reformadores del castigo en la llustración, entre ellos Bentham en An Introduction to the Principles of Moral and Legislation (1789), denunciaron el ejercicio ilegítimo del poder: la tiranía; y mostraron la necesidad de que el orden normativo del derecho, en lugar de vengarse, castigue. Además, la reforma no excluyó la consideración de motivos humanistas sobre la necesidad de reducir el sufrimiento causado por el castigo excesivo. Sin embargo, la carga principal de la justificación, en el caso de Bentham, Beccaria y otros utilitaristas, descansa en la finalidad del castigo, a saber, la reducción de la delincuencia (Beccaria, 2011).

Beccaria fue consciente del problema de este argumento, el cual si se lleva al extremo desemboca en peores castigos. En otros términos, aceptar sin más el principio de utilidad posibilita que los medios penales maximicen su fuerza y derive en castigos más severos. De ahí la necesidad de establecer una relación necesaria entre crimen y castigo que anule el atractivo de la idea de una acción reprobable. Frente a la simetría de la venganza, el castigo implica una respuesta completamente distinta: la transparencia del signo con lo que significa, a saber, una relación inmediatamente inteligible a los sentidos y que pueda dar lugar a un cálculo simple. Foucault denomina a esta operación por la que se vincula necesariamente el castigo con su pena, una “tecnología de la representación” (Foucault, 2018), que implica el control y manipulación de la representación de los intereses, de las ventajas y desventajas, del gusto y desagrado. De esta manera, el castigo ya no aparece como efecto arbitrario de un poder humano (Foucault, 2018), por el contrario, se ataca el exceso de los castigos, de su irregularidad, con lo que se busca establecer los principios de una nueva penalidad (Foucault, 2018). Así, el proyecto reformador de Beccaria, por ejemplo, relacionó estrechamente la abolición de la pena de muerte con el desarrollo de la prisión.

Siguiendo la genealogía trazada por Foucault en Vigilar y castigar: nacimiento de la prisión, la historia del crimen y el castigo muestra que la reforma llustrada de la ley criminal y la crítica a la arbitrariedad del sistema medieval, introducida a mediados del siglo XVIII, implicó el paso de la noción de castigo como suplicio (basado en el espectáculo del derecho monárquico o de la soberanía) a la reforma del castigo como pena (como signo y huella de una técnica de coerción moderna) (Foucault, 2018). De este modo, la defensa del derecho a castigar implica el desplazamiento de la venganza del soberano o monarca en la forma del suplicio a la defensa de la sociedad en el castigo (2018). El suplicio consiste en la remisión del castigo al crimen, éste indica 
la intervención del poder soberano, por medio de un signo que tiene como fin obstaculizar el castigo, e incluye toda una técnica de los signos punitivos (modelo inquisitorial). El castigo, por otra parte, constituye un instrumento económico, es una semiótica que cifra todos los comportamientos y busca reducir el campo de los ilegalismos, lo que implica un sistema vigilante de la conducta y vincula el aparato de justicia con un órgano de vigilancia directa: la policía (Foucault, 2018). Así, la ley reemplaza la voluntad del soberano, y el establecimiento del derecho del criminal a ser castigado reemplaza a la venganza.

El análisis histórico-genealógico del castigo, al indagar las causas económico, histórico y sociales, vinculadas a la constitución del poder en las instituciones, las prácticas o las formaciones de la subjetividad, parece, sin embargo, que no se pregunta por la legitimidad o la dimensión normativa del castigo. Como se mostrará, no todas las teorías que forman parte de la reforma Ilustrada de la ley penal justifican el castigo desde una estrategia utilitarista o relativa. Teorías como la de Kant y Hegel, justifican el castigo desarrollando argumentos de tipo retributivista o absolutos. Sin embargo, mientras que la teoría de Kant se inserta perfectamente en las estrategias y argumentos desarrollado por las teorías contractualistas y del liberalismo político, en el caso de Hegel es más difícil establecer las continuidades y rupturas con dicha tradición. Hegel, a diferencia de Kant y de la mayoría de las teorías utilitaristas, se distancia del liberalismo político y su teoría no se formula dentro del marco conceptual de la teoría general del contrato social. Para las teorías contractuales, una vez que el individuo entra en el contrato social, acepta de una vez y para siempre, junto con las leyes de la sociedad, que la sociedad puede castigarlo si incumple o viola la ley. Al romper el pacto en el crimen, se desvincula de la sociedad, y es por medio del castigo que simultáneamente se reincorpora a ella. El castigo, se constituye como ley y derecho desde donde se deduce su valor social y una nueva economía del castigo.

Como se verá en los siguientes apartados, aunque la argumentación de Hegel se distingue en varios puntos de la estrategia las teorías contractuales, sin embargo, su teoría se inserta en la reforma penal Ilustrada al sostener las mismas conclusiones. La reflexión hegeliana, al igual que Kant, se caracteriza por un análisis normativo por el que legitima el castigo; sin embargo, a diferencia de Kant, Hegel propone una teoría mixta de la pena que combina elementos las estrategias relativas y absolutas. El desarrollo de la pregunta por la legitimidad del castigo, formulada en el contexto del proyecto reformador llustrado, nos ayudará a distinguir algunos matices entre las teorías utilitaristas o relativas y las teorías absolutas o retributivistas, tal y como se verá en el caso de autores como Hobbes, Locke, Rousseau y Kant. Este breve recorrido ayudará a entender mejor la propuesta de Hegel e identificar sus aportaciones, problemas o desplazamientos.

\section{El castigo en la teoría política antes de Hegel}

Para Hobbes, la soberanía, entendida como poder del Estado, está autorizada por los ciudadanos por medio de un pacto fundacional. La soberanía encarna el poder colectivo que puede ejercerse contra los infractores de la ley. Sin embargo, Hobbes acepta que el soberano no puede esperar la obediencia por parte del ciudadano castigado y sostiene: 
...en definitiva, el motivo y fin por el cual se establece esta renuncia [a la autodefensa] y transferencia de derecho no es otro sino la seguridad de una persona humana, en su vida, y en los modos de conservar esta en forma que no sea gravosa (Hobbes, 2005, p. 109).

Esto se evidencia en que solo el contrato originario, por el que se establece la autoridad soberana, puede evitar "la guerra" en la que culmina el estado de naturaleza. De modo que, si el soberano amenaza la vida de los ciudadanos, elimina la razón por la que puede reclamar obediencia. Por ello, no se puede esperar que el ciudadano obedezca al ejecutor soberano, ya que en el castigo ambos se encuentran en un estado de guerra el uno con el otro, y en el estado de guerra no hay justicia ni injusticia. Frente a Hobbes, Locke se percata que, si no se puede justificar la justicia y la legitimidad del castigo, la autoridad del Estado para castigar equivaldría a su poder para coaccionar. Locke avanza así la discusión sobre la legitimación del castigo al incluir el derecho a castigar en la definición de poder político. “Considero, pues, que el poder político es el derecho de dictar leyes bajo pena de muerte y, en consecuencia, de dictar también otras, bajo penas menos graves [...] Y todo ello con la única intención de lograr el bien público" (Locke, 2006, p. 9). De este modo, deriva la legitimidad del castigo directamente de la naturaleza de la ley y sostiene que la legitimidad del Estado se establece a partir de la transferencia de los individuos de su derecho a castigar y en la relación estructural entre la ejecución de la ley y la autoridad soberana.

Hobbes y Locke no buscan responder la pregunta: ¿por qué castigamos? sino ¿qué derecho tenemos para castigar? Si la violencia o coerción infringida por el Estado o la sociedad no puede distinguirse claramente de la cometida originalmente por el infractor, la autoridad soberana descansaría en última instancia en la fuerza, es decir, solo en su poder de coacción (Hinchman, 1982, p. 526). Por ello, para Hobbes y Locke (como lo es para gran parte de la tradición política), el Estado debe poseer el monopolio sobre los medios de coerción y castigo. No obstante, afirman que el Estado no puede sostenerse solo por medio de la fuerza o la amenaza de la fuerza. El uso de la fuerza se acepta en la medida en que funciona como último recurso, dicho de otra forma, ante la falta o ruptura del pacto. De modo que, si el castigo es aplicado, este debe ser visto como legítimo y justo, no sólo como un acto de violencia, de lo contrario, el Estado se convierte en una máquina de coerción.

Será Rousseau quien tome el paso definitivo en la explicitación de la pregunta por la justificación del castigo. Para Rousseau, la fuerza o la violencia no pueden por sí mismas crear derecho, puesto que sólo estamos obligados a obedecer un poder legítimo. "Convengamos, pues, en que la fuerza no constituye derecho y en que únicamente estamos obligados a obedecer a los poderes legítimos" (Rousseau, 2017, p. 50). Así, la pregunta por la justificación del castigo se vincula explícitamente con la legitimidad del poder. La voluntad general es la encarnación del juicio de cada persona sobre las características básicas de la ley pública. Es el bien común y no los intereses particulares lo que constituye la legitimidad de la autoridad soberana. Al entrar en el pacto, el ciudadano adquiere la libertad social a cambio de la cesión de su libertad natural. Es 
así como el Estado legitima su autoridad para castigar, es decir, en cuanto parte de la voluntad general, cada ciudadano quiere las leyes que constituyen dicho pacto. Rousseau sostiene que la coerción contra el criminal es legítima porque solo así se le obliga a ser libre, es decir, al obligarlo a obedecer la ley que se ha dado a sí mismo. Porque me obedezco a mí mismo al obedecer las leyes,

En consecuencia, para que el pacto social no sea una fórmula vacía, contiene este compromiso tácito, que solo puede dar fuerza a los demás, y que consiste en que quien se niegue a obedecer a la voluntad general, será obligado por todo el cuerpo: lo que significa que se le obligará a ser libre (Rousseau, 2017, p. 65).

Para Hobbes, Locke y Rousseau, el castigo tiene dos rasgos fundamentales: en primer lugar, el castigo es una función legítima del Estado, que obliga al infractor en cuanto ejercicio del derecho y no del mero poder (coerción o fuerza). Por ejemplo, la ejecución, encarcelamiento, o imposición de trabajo forzado no constituye simplemente un asesinato, marginación o explotación disfrazada bajo el manto de la autoridad estatal, sino que sólo la coerción o violencia se transforma en castigo cuando es realizado por una autoridad legítima (Hinchman, 1982). En segundo lugar, Rousseau realiza un desplazamiento en las teorías liberales del castigo, al superar o desvincularse de las premisas individualistas del primer pensamiento político liberal de Hobbes y Locke. Es decir, el "yo" que forma parte de la voluntad general no es el mismo "yo" que el "yo" del estado de naturaleza. Al unirse a una comunidad abandona el "estado de la naturaleza" y con ello, renuncia a su identidad "natural” en favor de una identidad artificial, social, inseparable de los propósitos de la colectividad y que actúa como segunda naturaleza. Este desplazamiento es fundamental para entender la teoría sobre el castigo en Hegel y su rechazo o aceptación de la coacción del derecho. Al igual que Rousseau, Hegel desarrolla una teoría sobre la constitución del “yo" (la autoconsciencia), no como algo dado o abstracto, sino que se realiza y actualiza en la vida social (espíritu). Como se verá, Hegel completa el desplazamiento de Rousseau al legitimar el castigo, distinguiéndolo de la venganza. Hegel se separa de Hobbes y Locke al señalar algunos de los límites de las premisas liberales como son el individualismo y al rechazar la teoría contractual de la soberanía.

Antes de pasar al análisis de la teoría del crimen y castigo de Hegel, es necesario señalar el papel que la teoría de Kant ocupa en este breve recorrido histórico. La filosofía práctica de Kant avanza la teoría de Rousseau al transformar la voluntad general en el principio fundacional normativo de la moral y del derecho. Mientras que Rousseau limitó su concepción de la voluntad general a la fundación y funcionamiento del Estado; Kant ve en la teoría de la voluntad general la clave para fundamentar la libertad en su dimensión individual y social. Para Kant, la voluntad general es en realidad un caso especial del imperativo categórico, es decir, la ley aplicable en cualquier caso de acción moral. Hacer general mi voluntad significa preguntarme si el principio de mi acción puede ser elevado a ley universal (Kant, 2016). De este modo, el principio político de Rousseau está ahora "internalizado" en la conciencia de todo aquel que intenta cumplir su deber (Hinchman, 1982, p. 528). El derecho del Estado a castigar surge porque encarna, en el plano institucional, la voluntad racional de los ciudadanos. 
La justificación del castigo por parte de Kant, aunque forma parte de la tradición del contrato social y de la tradición liberal heredada por Hobbes, Locke o Rousseau, en su justificación normativa se deslinda de teorías relativas o utilitaristas del castigo. La teoría de Kant formula una justificación estrictamente normativa-conceptual, que, a diferencia de los teóricos de la prevención, no apela a consideraciones empíricas o pragmáticas, por ejemplo, a cuestiones de seguridad o eficiencia para la prevención del delito. Kant no apela al carácter disuasorio del castigo, ni basa su justificación en su función correctiva moral o social (2016, p. 166). Esto no significa que Kant niegue estas funciones, sino que, para él, son motivos incidentales que no demuestran la necesidad normativa del castigo. En la Metafísica de las Costumbres, Kant muestra la conexión a priori entre derecho y coerción a partir de una definición analítica: “el derecho está ligado a la facultad de coaccionar" (Kant, 2016, p. 40). El derecho es un obstáculo a la libertad (arbitrio) de acuerdo con leyes universales, y la coacción funciona como un obstáculo o una resistencia a determinados usos de la libertad. Por ende,

...si un determinado uso de la libertad misma es un obstáculo a la libertad según leyes universales, entonces la coacción que se le opone, en tanto que obstáculo frente a lo que obstaculiza la libertad, concuerda con la libertad según leyes universales; es decir, conforme al derecho (Kant, 2016, p. 40).

Siguiendo la teoría política Ilustrada contractualista, Kant sostiene que el individuo renuncia al estado de naturaleza y se somete a una coacción externa legal, por la cual otorga al Estado civil su poder natural de coacción (2016, p. 141). En cambio, el Estado, entendido como "la unión de un conjunto de hombres bajo leyes jurídicas” (2016, p. 142) le garantiza a éste el libre ejercicio de sus derechos, por ejemplo, su derecho a la propiedad. Según Kant, la ley es la voluntad de un pueblo/nación y es condición de posibilidad de la libertad del individuo dentro de la comunidad. Así, el fundamento de cualquier castigo está en la ley, en contraste con la arbitrariedad del gobernante, ya denunciada por la reforma penal Ilustrada. El crimen es toda transgresión de la ley pública e incapacita para ser ciudadano a quien lo comete (2016, p. 166). El derecho penal tiene como función asegurar al individuo y su propiedad al perseguir y castigar las violaciones de la ley. El derecho penal tiene el estatus del imperativo categórico y debe aplicarse solo como consecuencia ante una injusticia (2016, p. 166). Según Kant, el criminal comete un delito contra la comunidad en general al privar a los demás y a sí mismo de la seguridad. De modo que, el castigo es la única respuesta apropiada a una violación de la ley: al criminal debe sucederle lo mismo que él mismo cometió en el delito. Kant recupera el principio del talión, que establece que la relación entre crimen y castigo debe ser recompensada: “lo mismo por lo mismo" (2016, p. 167). Por consiguiente, al criminal no le queda más que aceptar su castigo; él mismo se ha vuelto contra las leyes, sus acciones son, por lo tanto, causales de su castigo. Kant se opone así a las teorías del derecho penal relativo o utilitarias, sobre la base de consideraciones de justicia, el castigo responde a un mal moral. Kant puede considerarse uno de los más importantes representantes de la teoría del derecho penal absoluto debido al énfasis puesto en la necesidad inmanente del castigo. 


\section{Crimen y coerción. La vulneración del derecho}

En los Fundamentos de la filosofía del Derecho, en el capítulo sobre El Derecho Abstracto, en la tercera sección sobre lo Injusto (das Unrecht), Hegel concibe el crimen como una forma de coerción, como un ejercicio de fuerza sobre la voluntad de otra persona en su dimensión objetiva. Es decir, como la violación del derecho abstracto de una o más personas particulares (Wood, 1990). En el parágrafo §92 Hegel sostiene que la coerción implica siempre un daño cuando es considerada abstractamente (GW 14, p. 88). Forzar o coaccionar son injustos cuando se les considerada en abstracto, es decir, cuando son substraídos de la relación social en la que necesariamente se inscriben. Para Hegel, la coerción siempre se encuentra situada en una relación social y sólo en esa relación puede juzgarse su legitimidad.

En los parágrafos §92 y §93, Hegel distingue entre una primera y una segunda coerción. Por coerción primaria entiende lo que hasta ahora hemos llamado coerción (Zwang) en su dimensión subjetiva y objetiva, es decir, una fuerza o violencia física (Gewalt) que genera un daño. Por ejemplo, el robo a la propiedad o cuando se amenaza con hacerlo como medio para hacer cumplir su voluntad. En este primer sentido, Hegel identifica el crimen con la coerción y rechaza toda la forma de coerción primaria (\$92). En el parágrafo §93 justifica la segunda forma de coerción argumentando que ésta posibilita la superación o cancelación de la primera, a partir de la cual se reestablece el derecho vulnerado. La legalidad de la coerción consiste en que es condición para superar la primera.

La manifestación del hecho de que la coerción se destruye (zerstört) en su concepto (Begriff) es que la coerción con la coerción se supera (aufgehoben), por eso no solo es jurídica (rechtlich) condicionalmente sino necesaria (notwendig), a saber, como segunda coerción (zweiter Zwang) que es una superación (Aufheben) de otra primera" (\$93) (GW 14, p. 88).

Así, Hegel define el crimen como una primera forma de coerción no legal y al castigo como una segunda coerción de carácter jurídico. En el parágrafo §94 Hegel caracteriza al Derecho Abstracto como,

\footnotetext{
...derecho coercitivo (Zwangsrecht) porque ejercer lo injusto (Unrecht) contra él significa ejercer una fuerza [violencia] (Gewalt) contra la existencia de mi libertad en una cosa exterior; la conservación de esa existencia frente a la fuerza (Gewalt) es así ella misma una acción exterior y una fuerza (Gewalt) que supera aquella primera (GW 14, p. 89).
}

En este parágrafo Hegel vincula, al igual que Kant, el derecho con su capacidad de ejercer coerción. Cabe destacar que la asociación aquí establecida es externa y limitada, y no postulada a priori, sino que es el resultado de la discusión sobre la legalidad y legitimidad del derecho para castigar. Tanto es así, que el mismo Hegel establece que esta relación solo es válida para el derecho abstracto (abstrakte) o estricto (strenge), ya que esta definición implica una concepción negativa del derecho como constricción (zwingen) o prohibición y ello supone pensarlo como 
"una consecuencia que solo se realiza por el rodeo de lo injusto (Unrecht)" (\$94) (GW 14, p. 89). En el parágrafo $\$ 38$ además afirma que el carácter esencialmente prohibitivo del Derecho Abstracto se debe a su carácter abstracto, y por eso "se limita a lo negativo, a no lesionar a la personalidad", de modo que este orden normativo sólo puede establecer prohibiciones jurídicas (Rechtsverbote) o leyes que se conciben solo como "un permiso o autorización” (GW 14, p. 52).

Las acciones éticas (no abstractas), es decir, la forma positiva de las leyes tiene, por el contrario, un contenido positivo como posteriormente mostrará Hegel en el capítulo sobre la Eticidad (Sittlichkeit). Para Hegel el derecho es legitimo cuando es "reconocido (anerkanntes), sabido (gewusstes) y querido (gewolltes) como universal y tener validez (gelten) y realidad objetiva (Wirklichkeit) a través de este ser sabido y querido" (\$209) (GW 14, p. 175). El derecho solo logra su existencia objetiva, si es conocido como "aquello que es justo y vale" (\$211) (GW 14, p. 175). Para Hegel, el derecho se realiza y concreta propiamente en la Sociedad Civil (\$217), es decir, deja de ser abstracto. En el Derecho Abstracto Hegel acepta que en el origen del derecho está lo prohibido como su fundamento (Grund). Con esta precisión, Hegel no sólo se separa de la definición a priori kantiana, sino que señala su restricción al ámbito del derecho penal (y no del derecho en su totalidad), al mismo tiempo que le otorga un rol esencial a la coerción y a la prohibición. Hegel se distancia de la definición kantiana que sostiene que "derecho y facultad de coaccionar significan, pues, una y la misma cosa" (2016, p. 42); ya que, para él, no podemos apelar directamente al significado o concepto de derecho para establecer que los derechos son ejecutables (enforceables), es decir, no es suficiente afirmar su autoridad para ejercer coerción contra sus infractores (Knowles, 2002). La identificación del Derecho Abstracto con el derecho coercitivo en el parágrafo $\$ 94$ no establece una definición ni una verdad analítica. Para llegar a esta conclusión es necesaria una demostración, al final del Derecho Abstracto Hegel mostrará sus limitaciones y señala las condiciones para su realización la dimensión institucional de la Eticidad (Sittlichkeit).

Para Hegel, el poder coercitivo no está incluido analíticamente en el concepto legal. Sino que se llega a él, como respuesta al daño o coerción primera, y, por tanto, como superación de lo injusto (Unrecht). Así, si bien el Derecho Abstracto se manifiesta como derecho coercitivo, esto no define esencialmente a la ley y su autoridad (Mohr 1997, p. 103). Para Hegel, el sistema del derecho no es coercitivo ni tiene como eje estructural el principio de sanción, sino que constituye el reino de la libertad realizada (\$4) (GW 14, p. 31), es decir, el derecho constituye el reino de la autorrealización de la voluntad libre, individual y colectiva. En el nivel del Derecho Abstracto, el castigo se determina por el derecho punitivo sin consecuencias negativas para el derecho en su totalidad. De modo que, si bien el derecho está ligado a la capacidad de coaccionar, esto no quiere decir que toda enunciación jurídica tenga explícitamente a la sanción o a la prohibición como principio. En la teoría de Hegel, el rol de la coerción (Zwang) y la fuerza/violencia (Gewalt) en la esfera del derecho penal está atravesada por la discusión sobre la relación entre derecho y justicia (Gerechtigkeit), lo que tendrá como consecuencia una teoría retributiva "modificada", diferente de la kantiana. Para Hegel, el derecho no solo establece el espacio normativo que define lo jurídico, en tanto prohibición o coerción, sino que constituye el ámbito de la justicia 
misma, y ésta no se limita a la esfera del Derecho Abstracto, sino que se realiza en la dimensión política y social, es decir, en la Eticidad (Sittlichkeit).

Hegel considera un acto criminal (Verbrechen) a la violación de la voluntad subjetiva del individuo y de la objetividad de la ley, y en ello consiste lo verdadero injusto (Unrecht). Se trata de crímenes como el robo o el asesinato, por ejemplo, en el que la voluntad particular del delincuente va en contra de la voluntad subjetiva de otro, la víctima, así como en contra de la voluntad existente de la ley (\$99) (GW 14, p. 91). Hegel sostiene:

No se trata solamente ni de un $\mathrm{mal}$, ni de hacer este o el otro bien, sino precisamente de lo injusto y de la justicia [...] lo único que importa es que el delito debe ser superado, y precisamente no como la producción de un mal (Übel), sino como vulneración del derecho en cuanto derecho (\$99) (GW 14, p. 110).

Así, el objetivo del castigo no es atacar un mal moral, sino el hecho de que la violación de la ley pone en peligro la relación jurídica como condición de la libertad humana y en tanto vulneración del derecho (Dübgen, 2016, p. 53).

Un acto criminal daña el derecho cuando atenta contra el espacio emergente del orden objetivo del derecho fundado en la autonomía como condición para ser persona, en la posesión de propiedad privada y en la posibilidad de establecer contratos. Sin ese espacio, la libertad no sería posible (Conklin, 2008, p. 146). Una vez presentada su tipología del crimen, Hegel centra su análisis en el crimen punible (Verbrechen) porque son precisamente estos los que representan un obstáculo para el derecho y exhiben un reto para su legitimidad. Como se formuló antes, si aceptamos que vivimos en un mundo en el que los derechos son exigidos y reconocidos como condiciones necesarias para la libertad, y simultáneamente aceptamos que estos derechos son rechazados en caso de su violación, entonces, se tiene que aclarar por qué y en qué casos la suspensión o violación de esos derechos está justificada por medio del castigo (y si el castigo es el mejor medio para hacerlo).

Hegel afirma que el crimen en cuanto vulneración del "derecho como derecho" (des Rechts als Rechts) en su dimensión objetiva, en cuanto existencia positiva, revela su falta de esencialidad en su nulidad (Nichtigkeit), es decir, en que puede ser aniquilada, en que es posible superarla. La realidad del derecho, por otro lado, consiste en "su necesidad mediadora consigo misma como superación de su vulneración” (\$97) (GW 14, p. 90). El castigo es la superación de la negación introducida por el crimen, y consiste en rechazar la negación del criminal de los derechos particulares en cuanto negación del orden normativo del derecho en su totalidad. La restitución del derecho consistirá en: por un lado, resarcir el daño a la víctima y, por el otro, reconocer la personalidad del criminal (en su derecho al castigo), así como su reincorporación al ámbito de los derechos que se le ha negado. Es decir, 
...desde la perspectiva objetiva como reconciliación (Versöhnung) de la ley que se reestablece así misma por la eliminación del delito, y por tanto como ley (Gesetz) que se realiza válidamente (gültig verwirklichen) y, desde la perspectiva subjetiva del delincuente (Verbrechers), como reconciliación de su ley sabida por él y válida para él y para su protección, en cuya ejecución (Vollstreckung) encuentra de este modo incluso la satisfacción de la justicia (Gerechtigkeit) (GW 14, p. 183).

Hegel considera la indemnización o resarcimiento como parte de la superación del crimen. En el parágrafo $\$ 98$ sostiene que la vulneración o daño a la existencia exterior o a la posesión es un mal (Übel) que implica "un daño en cualquier forma de propiedad o facultad" y "la superación de la vulneración como daño es la satisfacción civil como recompensa o sustitución (Ersatz), en la medida en que algo tal puede tener lugar" (GW 14, p. 91). Aquí parece Hegel estar consciente de que la indemnización o la reparación no es posible en todos los casos, piénsese en el caso de la violación o el asesinato. La introducción de esta consideración, así como la discusión sobre los derechos del criminal muestra el interés de Hegel por otro enfoque de la justicia que iría más allá de la justicia retributiva. Esta noción de justicia se parece más a lo que hoy denominamos justicia restaurativa. Un tipo de justicia que apunta hacia la reconciliación y la reparación y no tanto a la retribución, tal y como Hegel sostenía durante su período en Fráncfort en El espíritu del cristianismo y su destino (GW 2, p. 192). En Berlín, si bien su posición se inscribe ya en el marco de una teoría retributiva, no obstante, se puede argumentar que combina diferentes elementos que hacen de ella una teoría mixta.

\section{Castigo y justicia. Retribución y las limitaciones del Derecho Abstracto}

La interpretación más difundida sobre la teoría del castigo de Hegel sostiene que se trata de una teoría retributiva de la anulación en la que los castigos tienen la función de anular la ejecución de los delitos (Cooper, 1971; Houlgate, 1992). Las teorías retributivas son consideradas absolutas porque localizan la razón del castigo en el acto criminal mismo, a diferencia de las teorías relativas que justifican el castigo por los beneficios que aportan a la comunidad, así como su función preventiva. Por ejemplo, piénsese en Beccaria, quien cuestionó los fundamentos del castigo por su eficacia y coherencia para prevenir futuras violaciones de la ley. Contrariamente las teorías retributivas se refieren retrospectivamente a la reparación de los errores del pasado, apelando al valor superior de la justicia o a la conveniencia del castigo como modo de retribución (Dübgen, 2016). Dichas teorías sostienen tres tesis principales: a) los delincuentes solo pueden ser castigados si merecen el castigo, b) el castigo se justifica no en términos de sus efectos beneficiosos contingentes, sino de su justicia intrínseca como respuesta al acto delictivo y c) el valor del castigo debe ser proporcional a la naturaleza del correspondiente delito, sin apelar a consideraciones consecuencialistas, es decir, sólo se castiga a las personas responsables de cometer un delito (Brooks, 2007). De modo que, la atribución (criminalización) y el fallo (juicio) son condiciones necesarias y suficientes para el castigo. El retributivismo puede entenderse como una teoría individualista porque los únicos factores relevantes para su juicio están conectados al propio delincuente. Se castiga en proporción a lo que el criminal "merece”, es decir, en conexión con la maldad de sus intenciones al realizar un acto (pasado) (Brooks, 2007). 
Los factores que van más allá de las intenciones del criminal, como las consecuencias negativas de su crimen o la percepción pública, son irrelevantes para determinar el castigo.

La teoría retributiva de Hegel, tal y como la formula en su tratamiento del castigo en el Derecho Abstracto, sostiene que una persona solo puede ser considerada responsable del crimen si es realizó una coerción primera o daño y si existe una relación proporcional entre el valor de un crimen y su castigo (Brooks, 2007). Sin embargo, Hegel reformula la tesis sobre el valor del castigo en términos explícitamente sociales, es decir, en contraposición al individualismo característico del retributivismo clásico. Además, sostiene que la relación entre castigos y crímenes es sólo conmensurable nunca de igualdad específica (GW 14, p. 93-94). Con esta tesis, Hegel se opone al retributivismo clásico que sostiene una supuesta equivalencia estricta entre crimen y castigo, tal es el caso de la teoría del castigo de Kant y su recuperación de la ley del talión.

Como respuesta a lo injusto (Unrecht), Hegel argumenta que el derecho debe hacerse efectivo, ejecutarse (enforced). Para Hegel, esto implica la reafirmación de la voluntad común (expresada en el derecho) sobre la voluntad subjetiva. Hegel se refiere a esta "superación del crimen" como “retribución” en el parágrafo §101:

La superación (Aufheben) del delito es retribución (Wiedervergeltung) en la medida en que esta según el concepto es vulneración (Verletzung) de la vulneración y, según su existencia, el delito tiene un alcance cualitativo y cuantitativo determinado, por lo cual también tiene otro exactamente igual su negación (Negation) en cuanto existencia (GW 14, p. 93).

La retribución es el principal motivo que justifica los tratamientos correctivos, es decir, sobre la base de la imputación de la violación. Sin embargo, para Hegel la relación entre crimen y castigo no es de igualdad, sino que se establece “en términos de su valor" (\$101). En el parágrafo §99 Hegel discute las teorías relativas o preventivas del castigo y señala que el castigo no debe considerarse como un mal que vendría a anular otro mal. Para él, no tiene sentido "querer un mal (Übel) porque ya existe otro mal” (GW 14, p. 91). Este argumento apoya la idea de que no es función del derecho ejercer una primera coerción como medio para prevenir crímenes, el castigo solo puede ser una respuesta a un crimen entendido como coerción primaria.

Hegel rechaza los motivos pragmáticos de "las teorías de la prevención, de la intimidación, de la amenaza, de la corrección" porque niega que de un mal puede resultar algún bien (Gutes). "No se trata solamente de un $\mathrm{mal}$, ni de hacer este o el otro bien, sino, precisamente, de lo injusto (Unrecht) y de la justicia (Gerechtigkeit) [...] que es el punto de vista primero y sustancial del delito" (GW 14, p. 91). Esto no quiere decir que Hegel rechace la importancia de considerar la violencia psicológica y las consecuencias de la intimidación o sus efectos en la subjetividad del delincuente, para determinar la modalidad (Modalität) del castigo, es decir, para determinar el aspecto subjetivo del crimen. No obstante, no son fundamentales para determinar si el castigo es legal (rechtens) ni justo (gerecht). Hegel distingue entre la legalidad del castigo al interior de un orden normativo de derecho y la justicia como la condición que el castigo debe satisfacer para ser legítimo. 
Si bien la teoría de Hegel rechaza el uso de la coerción primera o su función disciplinaria como justificación principal para castigar, no se opone a las diversas formas que pueden adoptar los castigos concretos dentro de una comprensión más sustantiva del derecho (\$99). El castigo es así, una segunda coerción contra la voluntad del criminal y es necesario para el restablecimiento, o, mejor dicho, la reafirmación del derecho. "La vulneración (Verletzung) de esta voluntad en cuando existente es por tanto la superación del delito (aufheben des Verbrechens), que de otro modo sería válido, y es el restablecimiento del derecho (Wiederherstellung des Rechts)" (\$99) (GW 14, p. 90). La declaración de Hegel en §99 sostiene que si un derecho manifiesto es violado y el violador no es castigado (suponiendo que sea reconocido y disponible para el castigo, etc.) entonces debemos considerar su acto como inocente. Si ha tomado alguna propiedad, por ejemplo, debemos considerar esa propiedad como suya. Esto se apoya en la afirmación de que el acto criminal "de otro modo sería válido" (\$99) (GW 14, p. 90). Por el contrario, si se castiga al criminal se restablece públicamente la legitimidad del derecho ante el crimen con lo que se reivindica tanto el estatus moral de la víctima como sus derechos específicos. El acto no puede ser a la vez un crimen y un derecho (Knowles, 2002).

La relevancia del fallo pone el énfasis en la dimensión social del castigo, señala el reconocimiento por medio de la denuncia y el juicio. Sin criminalización y posterior tipificación no hay delito. Esto no significa que, si nadie descubre que sucedió el crimen, éste no haya ocurrido, sino que, si nadie declara que está mal, entonces, no lo está. La dimensión social del derecho no se encuentra, sin embargo, completamente reconocida en el Derecho Abstracto, no obstante, es un elemento esencial de la teoría de Hegel tal y como sostiene en el parágrafo §218. En la Eticidad, en la segunda sección sobre la Sociedad Civil (\$182-254) en el apartado sobre la Administración de la justicia, Hegel señala que los derechos (la propiedad y la personalidad) tienen validez y reconocimiento jurídico en la sociedad civil y que el delito no implica solamente la vulneración de la dimensión subjetiva, sino de la dimensión objetiva y universal del derecho y de las practicas sociales. Con lo que se introduce,

\footnotetext{
...el punto de vista de la peligrosidad de la acción para la sociedad, por lo cual, por una parte, se fortalece la magnitud del delito, pero por otra parte el poder de la sociedad — que ha devenido seguro de sí mismo - rebaja la importancia externa de la vulneración y origina en consecuencia una mayor suavidad en el castigo de la misma (GW 14, p. 181).
}

Como se puede ver, el retributivismo de Hegel es mínimo y consiste en la afirmación de (1) que el castigo sólo puede ser distribuido entre los culpables y (2) que debe haber una relación entre el delito y su castigo. Para Hegel, la justificación estrictamente punitiva del castigo es un relato incompleto sino incluye la discusión sobre la justicia del castigo, es decir sobre la legitimidad del derecho para castigar, por un lado, y la necesidad de su realización en las instituciones jurídicas del Estado y su función social, por el otro. No se debe olvidar que el castigo, en el Derecho Abstracto, surge como una reacción a la existencia de lo injusto (Unrecht). Por injusto, Hegel entiende un desprecio deliberado por el reconocimiento mutuo y por la legitimidad 
del derecho. Los castigos aspiran a restaurar el derecho, a restaurar las condiciones para ese reconocimiento. Sin embargo, el castigo, en el Derecho Abstracto, solo existe de forma contingente y a discreción de los particulares. Por ello sostiene Hegel, que los castigos, en el nivel del Derecho Abstracto, siguen siendo actos de venganza (\$102), ya que no existe aún un código penal de leyes y tipificación de los delitos, ni un poder penal institucionalizado para realizar el juicio por el que se establecen las penas de acuerdo con un código normativo vigente.

Para Hegel, donde no hay Estado, hay venganza (Brooks, 2007). En el Derecho Abstracto no existen todavía instituciones adecuadas para la administración de la justicia, ni tampoco leyes propiamente, solamente existe el derecho socialmente reconocido. Por ello, el Derecho Abstracto no logra transformar la venganza en justicia. Para Hegel, el castigo es legítimo solo en la dimensión de la Sociedad Civil, en el establecimiento del sistema judicial. Para él, sólo los tribunales pueden transformar la venganza en un castigo legal y legítimo. Esta tesis se opone a la interpretación dominante que sostiene que la teoría del castigo de Hegel está contenida sustancialmente en el apartado del Derecho Abstracto (Cooper, 1971 y Houlgate, 1992, véase también Steinberger, 1983 y Houlgate 1992). Si aceptamos la tesis aquí defendida, entonces se tendría que concluir que los delitos y sus correspondientes castigos dependen esencialmente del Estado de derecho y las instituciones judiciales. Además, la tesis reduccionista al Derecho Abstracto no explica cómo se logra superar la venganza al nivel de Derecho Abstracto. Hegel que identifica castigo y venganza en el parágrafo §102: “la pena conserva todavía en sí por lo menos una parte de venganza" (GW 14, p. 95). Para alcanzar la justicia, se tiene que eliminar la arbitrariedad del castigo y por ello, es fundamental la distinción que hace entre dos tipos de coerción, a partir de la cual rechaza la primera como ilícita y justifica la segunda no solo como legal sino legítima.

La noción de castigo en el Derecho Abstracto es distintiva porque es diferente de lo que contemporáneamente entendemos por pena (legal), principalmente porque no es una respuesta al incumplimiento de la ley (esta concepción es introducida hasta la Sociedad Civil). El castigo, entendido como segunda coerción, es una respuesta a la existencia de lo injusto (Unrecht), mientras que la pena es una respuesta a la violación de la ley (Brooks, 2017). En el Derecho Abstracto, el castigo es necesario para reestablecer las condiciones que el crimen vulneró, y que permiten el reconocimiento mutuo. En esta dimensión, la libertad consiste en el acuerdo de estipulaciones particulares entre dos personas. El crimen es el incumplimiento o vulneración de dicho acuerdo. El castigo promueve y salvaguarda el reconocimiento mutuo mostrando que a la base de la voluntad particular está la comunidad que asegura dicha interacción. También demuestra que sólo en una comunidad donde existe el reconocimiento mutuo puede el libre albedrío actuar sin caer en la arbitrariedad y así evitar la venganza. De acuerdo con esta interpretación, lo fundamental para la teoría de Hegel es garantizar una respuesta a la acción transgresora del criminal. Sin embargo, no parece esencial que la forma del castigo sea de naturaleza retributiva, siempre y cuando se haga justicia y se reestablezca la relación del criminal con su comunidad. 


\section{Conclusiones}

Con la introducción de la discusión sobre la legitimidad del castigo en el Derecho Abstracto, Hegel desplaza la pregunta por la venganza anclada en la dimensión de las relaciones interpersonales por la pregunta por la legitimidad del derecho para ejercer coerción, basada en la dimensión social del castigo e institucionalizada de la administración de justicia. Este cambio en la estrategia mostró que la la legitimación de la coerción como castigo sólo se logra en la dimensión de la Administración de la justicia en el apartado de la Sociedad Civil. La teoría de Hegel al interrogarse por la legitimación del castigo se inserta y continua el debate comenzado por la reforma penal Ilustrada. Sus críticas y distanciamientos de la teoría contractual y de algunos de los principios del liberalismo político desplazan en su teoría, la pregunta por la legalidad del castigo hacia el cuestionario de la noción moderna de derecho y una investigación de los fundamentos del orden político, transformando la noción misma de soberanía.

Hegel muestra que, si el orden normativo del derecho falla en superar o eliminar el crimen, el crimen al establecerse como válido, hace del arbitrio del criminal un universal. Por ello, es que el derecho debe castigar, si no lo hace puede comprometer la legitimidad de la dimensión objetiva del derecho. Un acto criminal niega la legitimidad del orden normativo, por ello es necesario devolverle a este último su universalidad, pero no por un acto de violencia, como lo sería la coerción primaria, en cuanto afirmación autoritaria o imposición violenta que subsumiría al delincuente a un poder soberano (venganza), sino la mediación que implica el reconocimiento del criminal, por medio de una segunda coerción en la forma de la pena (Strafe), asegurada por la administración de justicia y el poder de la sociedad civil. Para Hegel, la ley tiene que ser vinculante incluso para el criminal, sólo así se asegura su justicia. Si la ley se impone por medio de una coerción primera (Zwang) o de forma físicamente violenta (Gewalt), la ley no es expresión de la libertad. Para él, la ley no está por encima de la voluntad de las personas, el crimen sólo logra desafiar su legitimidad porque la ley descansa en la voluntad libre y en la observancia voluntaria del agente.

Se puede concluir, que Hegel no sólo se opone a una teoría exclusivamente retributiva, como la de Kant, sino que redefine la idea de castigo al mezclar razones absolutas y relativas. La diferencia entre Hegel y Kant es que Hegel no ofrece una definición analítica del castigo, ni una justificación estrictamente conceptual sobre la relación entre derecho y coerción, sino que cuestiona la legitimidad del derecho para ejercer coerción (y sus prácticas), y se pregunta por sus consecuencias sobre la agencia del criminal. Si bien, la retribución exhibe, según Hegel, racionalidad, ésta atenta contra la libertad del individuo si se acepta sin más el uso de la coerción. En los Fundamentos de la filosofía del Derecho, Hegel justifica no sólo la legalidad de la coerción, rechazando cualquier forma de coerción primaria a la que vincula con la venganza, además, sostiene la racionalidad y compatibilidad del castigo con la libertad, al mostrar su legitimidad, con lo asegura su justicia. Hegel defiende, con su teoría mixta de la pena jurídica, la necesidad de superar el daño contra el sistema de derecho, y argumenta en favor de la rehabilitación 
de la voluntad del criminal al afirmar que el castigo es justo y es su derecho. Con estas dos tesis Hegel avanza no sólo algunas de los retos abiertos por Hobbes, Locke, Rousseau y Kant, también señala algunos problemas fundamentales para la teoría contractualista y liberal de estos autores.

\section{Referencias}

Beccaria, C. (2011). De los delitos y las penas. Fondo de Cultura Económica.

Bentham, J. (1996). An Introduction to the Principles of Morals and Legislation. Clarendon Press.

Brooks, T. (2007). Hegel's Political Philosophy. A Systematic Reading of the Philosophy of Right. Edinburgh UP.

Brooks, T. (2017). Hegel's Philosophy of Law. En D. Moyar (Coord.), The Oxford Handbook of Hegel, (pp. 32-62). Oxford UP.

Cooper, D. E. (1971). Hegel's Theory of Punishment. En Z. A. Pelczynski (Coord.), Hegel's Political Philosophy. Problems and Perspectives, (pp. 151-67). Cambridge UP.

Conklin, W. E. (2008). Hegel's Laws. The Legitimacy of a Modern Legal Order. Stanford UP.

Dübgen, F. (2016). Theorien der Strafe zur Einführung. Junius.

Foucault, M. (2018). Vigilar y castigar: nacimiento de la prisión. Siglo XXI Editores.

Hegel, G. W. F. (GW). (1968). Gesammelte Werke. Verbindung mit der Deutschen Forschungsgemeinschaft (DFG) herausgegeben von der Nordrhein-Westfälischen Akademie der Wissenschaften und der Künste.

Hegel, G. W. F. (1991). Elements of the Philosophy of Right, Ed. by Allen Wood, trans. H.B. Nisbet. Cambridge UP.

Hegel, G. W. F. (2009). Grundlinien der Philosophie des Rechts. Felix Meiner Verlag.

Hegel, G. W. F. (2014). El joven Hegel. Ensayos y esbozos, trad. José María Ripalda. Fondo de Cultura Económica.

Hegel, G. W. F. (2015). Fundamentos de la Filosofía del Derecho, trad. Carlos Díaz. Fontamara.

Steinberger, P. J. (1983). Hegel on Crime and Punishment. The American Political Science Review, 77(4), 858-870. https://doi.org/10.2307/1957562

Hobbes, T. (2005). Leviatán: o la materia, forma y poder de una república, eclesiástica o civil. Fondo de Cultura Económica.

Houlgate, S. (1992). Hegel's Ethical Thought. Bulletin of the Hegel Society of Great Britain, 13(1), 1-17. doi:10.1017/S026352320000481X

Kant, I. (1900). Gesammelte Schriften, Hrsg. von der Preußischen Akademie der Wissenschaften (Bd. 1-22), Deutsche Akademie der Wissenschaften zu Berlin (Bd. 23), Akademie der Wissenschaften zu Göttingen. Berlin.

Kant, I. (2016). Metafísica de las Costumbres, trad. Adela Cortina y Jesús Conill. Tecnos.

Knowles, D. (2002). Hegel and the Philosophy of Right. Routledge.

Locke, J. (2006). Segundo tratado sobre el gobierno civil. Un ensayo acerca del verdadero origen, alcance y fin del Gobierno Civil. Tecnos. 
Mohr, G. (1997). Unrecht und Strafe. En L. Siep (Coord.), G.W.F. Hegel: Grundlinien der Philosophie des Rechts, (pp. 95-124). De Gruyter.

Rousseau, J. (2017). El contrato social. Akal.

Wood, A. W. (1990). Hegel's Ethical Thought. Cambridge UP.

\section{AUTORA}

Ana María Miranda Mora. Doctora en Filosofía, Universidad Nacional Autónoma de México (UNAM), México. Es actualmente docente en la Alice Salomon Hochschule Berlin, Alemania. Ha sido docente en la Facultad de Filosofía y Letras de la UNAM y en la Universidad del Claustro de Sor Juana, Ciudad de México. Sus áreas de investigación se concentran en: idealismo alemán (especialmente Hegel y Kant), Filosofía política moderna y contemporánea (especialmente Hegel, Marx, Engels, Benjamin, Foucault), Feminismos post/decolonial, Latinx Feminism. 